\title{
TRABALHO, EDUCAÇÃO E SOCIEDADE: A FORMAÇÃO DO TRABALHADOR NO ÂMBITO DAACUMULAÇÃO DO CAPITAL
}

\author{
Fabiane Santana Previtalli \\ Universidade Federal de Uberlândia \\ fabianesp@netsite.com.br \\ Maria Vieira Silva \\ Universidade Federal de Uberlândia \\ mvs@ufu.br
}

\section{RESUMO:}

O objetivo deste trabalho é discutir em uma perspectiva histórica, tomando como referência a via de acumulação taylorista-fordista do capital e a via da acumulação flexível, a relação trabalho e educação, problematizando as diferentes dimensões entre organização e controle do trabalho, capacitação e qualificação profissional. Busca-se analisar quais são e até que ponto um conjunto de novas qualificações e habilidades demandadas pelas empresas estão implicando em maior autonomia do trabalhador no chão de fábrica e revertendo a extrema divisão entre concepção e execução do trabalho, pilar do padrão de acumulação taylorista-fordista. Entende-se que historicamente o capital se apropria dos saberes da classe-que-vive-do-trabalho, aplicando-o, enquanto técnica, à produção de mercadorias, resultando em um constante processo de desqualificação profissional e intensificação do trabalho. As analises estão fundadas em estudos de casos de setores econômicos ${ }^{* * *}$.

Palavras-chave: processo de trabalho, trabalho, habilidades, qualificação, estudo de caso.

\section{WORK, EDUCATION AND SOCIETY: THE TRAINING OF WORKERS IN THE CAPITAL ACCUMULATION}

\begin{abstract}
:
The aims of this paper is to discuss in a historical perspective, taking as reference the route of Taylorist-Fordist accumulation of capital and means of flexible accumulation, the work and education, problematized the different dimensions of organization and control of labor process, training and qualification. Try to analyze what and to what extent a set of new qualifications and skills demanded by business are resulting in greater autonomy of the worker in the shop floor and reversing the extreme division between intellectual and execution of work, a pillar of the pattern of accumulation-Taylor Fordist. It is understood that historically the capital of knowledge is appropriate for class-who-lives-of-work, using it as a technique for the production of goods, resulting in a constant process of professional deskilling and intensification of work. The analysis is based on case studies of economic sectors.
\end{abstract}

Key-Words: labor process, work, skills, qualification, case studies.

\section{Introdução}

Durante as últimas décadas as economias capitalistas desenvolvidas e em desenvolvimento vêm sofrendo profundas transformações. Observa-se um intenso processo de reestruturação produtiva do capital através da integração dos mercados financeiros, fundamentada, por sua vez, no novo ideário político neoliberal de livre comércio e de uma 
menor presença do Estado como poder regulador das relações entre capital e trabalho. $\mathrm{O}$ conjunto desses elementos esta implicando no retrocesso de conquistas sociais e caracterizando um período com características "neoconservadoras" com grandes perdas para a classe trabalhadora.

As transformações estão associadas a um processo de reestruturação das formas de organização e controle do trabalho ao longo das cadeias produtivas, através das quais o capital busca romper com a estrutura político-institucional de regulação que lhe proporcionou crescimento e relativa estabilidade durante o período taylorista-fordista. Por um lado, a reestruturação produtiva visa responder à crise que se instaura no regime taylorista-fordista de acumulação a partir da segunda metade da década de 1970. Por outro lado, está implicando na construção de uma nova ordem de acumulação, porém, ainda circunscrita à lógica da reprodução do capital e fundada na dinâmica histórica das lutas de classes.

O processo de reorganização do trabalho está originando uma forma de controle do processo produtivo mediante a introdução de tecnologias de informação ${ }^{i}$ e práticas gerenciais, cujo discurso assenta-se na cooperação, no envolvimento e na parceria do trabalhador. Nesse contexto, onde as palavras de ordem passaram a ser flexibilidade e qualificação, as empresas observaram que muito do processo de inovação, particularmente as inovações incrementais ${ }^{\text {ii }}$ no processo de trabalho, dependem da participação do trabalhador direto. Quanto mais motivado e envolvido ele estiver com os objetivos da empresa, maiores serão as possibilidades de ocorrência de pequenas mudanças operacionais que impactarão de forma significativa na redução de custos, bem como na eficiência do processo produtivo e, dessa forma, a empresa estará melhor adaptada às condições de concorrência no mercado. As mudanças sugeridas pelos trabalhadores incluem adaptação de ferramental, agilidade de transporte de peças e de comunicação interna, apresentação do produto, uso mais racional de matérias-primas e de pessoal, visando à eficiência. Estudos têm demonstrado que, ao sugerir tais mudanças, o trabalhador acaba por colaborar com a gerencia administrativa, indicando-lhe onde o trabalho pode ser feito por menos pessoas e/ou em menor tempo, o que implica em demissões e/ou intensificação do trabalho (PREVITALLI, 2006a; PREVITALLI, FARIA, 2008).

Dessa forma, as empresas almejam o controle sobre uma capacidade de produção subjetiva, cognitiva, e sua aplicação no processo de inovação. Cumpre dizer que até então o trabalhador não era chamado a pensar sobre o seu trabalho. Ao contrário, Taylor desejava um "gorila adestrado", que soubesse executar as ordens da gerência científica. (BRAVERMAN, 1977). As novas práticas gerenciais buscam a colaboração e o envolvimento dos trabalhadores de chão-de-fábrica através de pagamentos de prêmios individuais. Mas esse elemento por si só não é uma novidade no campo do controle dos trabalhadores e quebra de solidariedade de classe. A novidade consiste no desenvolvimento de mecanismos que constrangem esses trabalhadores a participar da gestão do seu trabalho. Portanto, esses trabalhadores passam a ser co-gestores do processo de racionalização do processo de trabalho. Essas práticas de gestão, a difusão das inovações tecnológicas no processo produtivo, bem como as formas flexíveis de contratação, tais como: trabalhadores temporários e em tempo parcial, estão criando dificuldades para a ação dos sindicatos, reduzindo seu poder de representação junto à classe trabalhadora e, nesse sentido, tornando imprescindível que ele também passe por um processo de reestruturação.

Vale dizer que a fábrica moderna nasceu mais da observação e apropriação do saber do artesão do que da incorporação do conhecimento científico à produção de mercadorias, como bem demonstra Marx (1988) na análise da transformação do trabalho artesanal até a 
grande indústria. É nesse sentido que a problematização da relação entre trabalho e educação assume uma extrema relevância.

\section{1-Considerações sobre Trabalho e Formação dos Trabalhadores no Capitalismo}

$\mathrm{Na}$ abordagem marxiana, o trabalho é considerado atividade exclusivamente humana, meio de relação Homem-Natureza. Ele é um elemento de mediação entre Homem e Natureza no processo de produção e reprodução de sua existência sócio-cultural. No processo de produção o homem não apenas modifica o material ao qual deseja satisfazer suas necessidades, ele concretiza neste material um projeto anterior criado conscientemente. Coloca em ação não apenas as suas potencialidades naturais, mas também retira as potencialidades existentes na natureza e as coloca em seu favor. É nesta atividade fundante da existência humana em que o trabalho adquire forma e atributos condicionados sócio-historicamente. É no momento em que o homem interage com a natureza alterando-a para a satisfação de suas necessidades essenciais e alterando concomitante sua própria natureza, que os homens entram em relações uns com os outros com o mesmo fim, ou seja, instituem relações sociais de produção.

$\mathrm{Na}$ medida em que, ao produzir, os homens atuam coletivamente, cooperam, a produção da vida, tanto a própria como a alheia através da procriação, surge-nos agora como uma relação dupla: por um lado, como uma relação natural e, por outro, como uma relação social - social no sentido de ação conjugada de vários indivíduos, não importa em que condições, de que maneira e com que objetivo (MARX, ENGELS,1989:16).

A partir das relações sociais no ato de produção do real se formam todos os subsequientes arranjos estruturais dos homens em sociedade que, por sua vez, irão também condicionar as relações materiais de produção. São as relações sociais de produção que determinam, por conseguinte a divisão social do trabalho. Sendo assim, dadas relações sociais de produção e consequientemente a divisão social do trabalho que aquela engendra, os homens determinam as formas de produção e distribuição dos produtos. Uma vez que os critérios em que se fundamenta não se pautam pela igualdade, dividem-se em classes sociais historicamente antagônicas.

A estrutura social em classes pressupõe interesses divergentes e conflitantes, à medida que os sujeitos necessitam da mesma forma satisfazer suas necessidades naturais, seja pela exploração do trabalho alheio ou do seu por outrem. O antagonismo de classes não advém de convenções instituídas ao longo da história. Ele advém da básica necessidade humana de produzir e reproduzir suas condições materiais de existência sob condições sociais determinadas, condições de conflito e contradições às quais para a análise marxiana é concebida como mola propulsora do processo histórico. A separação entre classes antagonicamente interdependentes se baseia na propriedade ou não dos meios de produção, que por sua vez, funda-se no trabalho alienado. Ou seja, a propriedade privada é, por um lado, produto do trabalho alienado e, por outro lado, é o meio pelo qual o trabalho se torna alienado (FROMM, 1979).

O trabalho enquanto atividade essencialmente humana e criadora torna-se trabalho alienado quando passa a ser externo ao trabalhador, sendo trabalho forçado por outro. "O seu caráter exteriorizado é demonstrado por não ser o trabalho dele mesmo, mas trabalho para outrem, por no trabalho ele não se pertencer a si mesmo, mas a outra pessoa" (MARX, 1979: 93). A introdução de inovações tecnológicas e organizacionais no processo 
produtivo é uma constante no modo de produção capitalista. Marx (1988) foi um dos primeiros pensadores a tratar esses elementos como endógenos ao processo de acumulação capitalista, analisando-os no contexto da luta de classes sociais. Cumpre ressaltar que a teoria de Marx sobre o processo de trabalho está intimamente relacionada com sua teoria das classes sociais, sendo o conceito de classe construído a partir das formas de apropriação do trabalho excedente que, por sua vez, relaciona-se com as formas de propriedade, ou seja, a propriedade ou não dos meios de produção (PREVIRTALLI, 2002; PRVITALLI, 2005; FARIA, PREVITALLI, 2008).

Segundo Marx (1988), o processo de trabalho no capitalismo consiste em um processo de valorização do capital, sendo o seu objetivo principal o aumento da produção da mais valia. A questão que se coloca para o capital é a de como aumentar a produção da mais valia independentemente do prolongamento da jornada de trabalho. Esse processo torna-se possível através da redução do tempo de trabalho necessário - a parte do tempo que o trabalhador utiliza para si mesmo - e aumento do mais trabalho, que corresponde ao tempo de trabalho para o capitalista. Dessa forma o capital aumenta a força produtiva do trabalho “(...) mediante mudanças nos meios de trabalho ou nos métodos de trabalho ou em ambos" (MARX, 1988:238) e o processo de valorização do capital passa a se estabelecer através da mais valia relativa.

Portanto, o capital realiza a mais valia relativa através de um processo de mudanças nos meios de produção e métodos de organização do trabalho por meio da aplicação da tecnologia, que por sua vez, reduz o valor da mercadoria e da força de trabalho. Há um estímulo individual do capitalista para a redução do tempo de trabalho necessário que é o barateamento da mercadoria devido à concorrência dos demais capitalistas. A concorrência, assim, impele o capitalista a transformar as condições técnicas e sociais do processo de trabalho através da apropriação do saber dos trabalhadores (Marx, 1988). Nesse sentido,

\footnotetext{
“(...) a mesma lei da determinação do valor pelo tempo de trabalho que se fez sentir ao capitalista com o novo método na forma de ter que vender sua mercadoria abaixo de seu valor social, impele seus competidores, como lei coercitiva da concorrência, a aplicar o novo modo de produção" (MARX, 1988: 241).
}

O capitalista que introduz as mudanças no processo produtivo tem a possibilidade de apropriar-se de maior parte da jornada de trabalho para o mais trabalho do que os demais capitalistas que ainda não o fizeram. Entretanto, essa mais valia extra, obtida quando o capitalista individual consegue obter maior lucro que os demais, desaparece à medida que a mudança se generaliza na economia capitalista (MARX, 1988). Assim, o aumento da força produtiva do trabalho estende-se pelos ramos da produção, por um lado, barateando a mercadoria e, por outro lado, reduzindo o valor da força de trabalho. Nas palavras de Marx (1988),

“(...) é impulso imanente e tendência constante do capital aumentar a força produtiva do trabalho para baratear a mercadoria e, mediante o barateamento da mercadoria, baratear o próprio trabalhador" (MARX, 1988: 242).

Há, dessa forma, um estímulo intrínseco ao modo de produção capitalista que faz com que o capitalista queira investir em novas técnicas de produção e organização do 
trabalho, alterando as forças produtivas. De acordo com Marx (1988), o que distingue as diferentes épocas econômicas.
“(...) não é que se faz, mas como, com que meios de trabalho se faz. Os meios de trabalho não são só medidores do grau de desenvolvimento da força de trabalho humana, mas também indicadores das condições sociais nas quais se trabalha" (MARX, 1988: 144) ${ }^{\mathrm{iii}}$.

A formação do modo especificamente capitalista de produção é caracterizada quando um único capital consegue subjugar sob um mesmo espaço físico uma quantidade considerável de capacidades de trabalho a fim de produzir mercadorias em grande escala. Como resultante de um processo histórico, a consolidação da forma específica de produção capitalista só é construída à medida que as sociabilidades pautadas pelo capital revolucionam suas bases de produção. Tem-se assim, um período de metamorfose das relações entre capital e trabalho que perpassam a cooperação simples e a manufatura caracterizadas por uma subsunção formal do trabalho ao capital e a grande indústria, a forma específica ou consolidada capitalista, a qual pressupõe uma subsunção real do trabalho ao capital.

Tal aproximação embora não explícita, é feita, sobretudo a partir dos estudos dos capítulos históricos do Capital (cooperação, manufatura e grande indústria) e no capítulo VI (inédito do Capital) em que Marx trabalha os resultados do processo de produção imediato. A cooperação simples esteve presente em todas as formas de produção coletiva anteriores ao capitalismo. Mas o que distingue a concepção de cooperação utilizada pelo capital em relação aos outros modos de produção

"é a coação que se exerce, isto é, o método pelo qual o sobretrabalho é extorquido. (...) a essa coação é dada apenas uma forma distinta da que tinha nos modos de produção anteriores, uma forma, porém que aumenta a continuidade e a intensidade do trabalho (...)" (Marx, 1988:95).

Como embrionária da manufatura e em longo prazo da própria maquinaria, a cooperação é considerada como a primeira forma em que o capitalista (personificação do capital) subjuga o trabalho humano a um processo de valorização ao empregar considerável capacidade de trabalho. Considerável aqui designa grandes quantidades de capacidade de trabalho de forma simultânea, em contraposição às formas de produção anteriores, por exemplo, a produção doméstica. A diferença consiste que num mesmo espaço e num tempo delimitado e menor, o capitalista através da cooperação dos trabalhadores consegue mobilizar as capacidades produtivas a produzirem de tal forma, que se convertam de trabalhadores individuais a um "trabalhador coletivo".

O dia de trabalho combinado de 144 horas que ataca o objeto de trabalho de diversos lados faz avançar a produção total mais rapidamente do que 12 dias de trabalho em 12 horas, realizados por um trabalhador isolado. É que o trabalhador coletivo tem olhos e mãos em todas as direções e possui dentro de certo limite, o dom da ubiqüidade. Concluem-se ao mesmo tempo diversas partes do produto que estão separadas no espaço. (MARX, 2004:380).

Para que esta revolução das condições de produção possa ocorrer, ou seja, para que o capitalista possa converter capacidades de trabalho individuais em trabalhadores 
coletivos, o mesmo deve também se dispor de uma quantidade de capital necessário para adiantar aos trabalhadores desconexos entrarem em conexão no momento da produção. Tal conexão não é apenas mais produtiva pelo caráter combinado de capacidades de trabalho sob um mesmo objeto, como advém do próprio contato entre os trabalhadores no processo produtivo denominado por Marx como emulação, impulsionando-os na produtividade. Para isto, terá o capitalista também de ter considerável quantidade de capital para dispor de meios de produção em quantidades equivalentes ao número de trabalhadores combinados em ação. Ou seja, a fim de que o processo possa ser efetivo, a quantidade de meios de produção deverá ser equivalente ao "tamanho do trabalhador coletivo" a fim de que, o tempo de produção possa realmente ser diminuído pela quantidade de braços empregados simultaneamente.

Tal processo pertence à subordinação formal do trabalho ao capital, pois já aí implicitamente o que verificamos é uma constante preocupação do capitalista exatamente com o tempo de produção. Ainda que de forma rudimentar referente à suas formas posteriores, a cooperação enquanto processo de trabalho expressa um dos pilares da produção capitalista, a diminuição do tempo de trabalho necessário e aumento do tempo excedente de produção. Necessariamente a cooperação já instituída num acúmulo de trabalhadores, prescreve a observância e o controle do capitalista quanto ao tempo de produção, quando consideramos a maior resistência por partes destes trabalhadores em conjunto. Para isto sua atividade de fiscalização não apenas se faz necessária enquanto controle do processo produtivo, mas também para harmonizar e manter sempre em conexão as diferentes atividades particulares que formam o trabalhador coletivo.

Mais ainda, o que está realmente em jogo neste processo é o embate entre resistência dos trabalhadores e dominação do capitalista, à condição de exploração. Cabe ressaltar ainda que a produtividade alcançada pelo trabalhador coletivo aparece não obstante aos trabalhadores como produtividade do próprio capital, ensejando já desde seu início, numa alienação dos trabalhadores em relação ao processo produtivo ao qual são protagonistas e não coadjuvantes. À medida que se desenvolve tal processo de produção e o capitalista aumenta sua significância de capital a ser investido, verifica-se que o mesmo se despoja destas funções de supervisão e de controle direto dos trabalhadores e emprega um tipo de trabalhador especificamente treinado e remunerado para esta função, os gerentes em um estado germinal.

Da divisão do trabalho na cooperação, segue-se à manufatura. Esta pode ser considerada como um salto qualitativamente divergente em relação à cooperação, pois neste sistema de produção, pôde o capitalista avançar sua ofensiva em relação aos trabalhadores, seja por meio da aquisição dos meios de produção e principalmente pela cooptação do saber produtivo acumulado em seu ofício (PREVITALLI, 2005, FARIA, PREVITALLI, 2008), principalmente dado o prrocesso de parcelização do trabalho. Agora os trabalhadores que antes dispersos pela qualificação de seus diferentes ofícios são definitivamente reunidos sob um mesmo espaço físico e a diferenciação existente na natureza de seus ofícios, dá lugar às atividades parciais.

O processo de especialização em tarefas dos antigos ofícios artesãos possuiu efeitos bastante práticos e lucrativos sob a ótica do capital. Sob um primeiro ponto de vista, o capitalista consegue reunir os trabalhadores de diferentes ofícios e anteriormente independentes, conectando-os. A conexão empreendida pelo capitalista só veio a ser efetivada quando as diferentes etapas de um mesmo trabalho em particular, são parceladas e tornadas autônomas em relação ao ofício a que pertenciam. O trabalhador que antes era responsável por todas as etapas componentes da fabricação de uma mercadoria qualquer, agora tem seu ofício especializado em algumas tarefas simples. Ainda que seja indubitável 
a revolução ocasionada na base produtiva pela intensificação da produção fabril, convém ainda explicitar os efeitos da introdução do processo científico nestas relações sociais de produção, seja pela maquinaria como também por parte da gerência científica.

Conforme a literatura, a maquinaria é caracterizada pela transformação dos instrumentais de trabalho, pela transformação das ferramentas em máquinas ferramentas. Conforme a distinção clássica de Marx, a principal diferenciação entre máquina e ferramentas diz respeito à sua força motriz, tendo a segunda a força humana, e a primeira uma força diversa da humana, a saber, "a de um animal, a da água, a do vento, etc." (MARX, 2004:428). Neste contexto, dado que existe a adaptação do trabalho a forças motrizes alternativas a humana, as máquinas não são características peculiares deste período histórico. O homem na produção e reprodução de seu real, sempre se utilizou tanto de ferramentas quanto de máquinas desde a domesticação de animais como forças motrizes. A implementação da maquinaria enquanto forma de se assim ser das relações capitalistas de produção teve que destituir do comando humano de produção, duas grandezas significativas: o ofício manual (representado pelo mecanismo de transformação de matérias primas em produtos) e a força motriz.

Logo que a Revolução Industrial se vê consolidada tem-se que o primeiro processo já se encontra resolvido. A maquinaria situa-se na potencialização da produtividade do instrumental de trabalho. Potencializa-se o poder de transformação e consumo de trabalho vivo ainda que a força motriz esteja vinculada ao processo humano e que sua nova função seja a partir deste momento, o de vigiar e corrigir as imperfeições do autômato fabril. Na verdade, revoluciona-se o consumo de trabalho vivo por trabalho morto ao romper com a barreira existente pelo número de ferramentas que cada trabalhador pode manusear.

A aplicação da máquina a vapor no processo produtivo tem dois efeitos bastante práticos à valorização do capital: o controle pelo avanço dos antigos limites naturais e a conseqüente constância do processo de produção, operados e controlados pela personificação do capital e não pelos reais protagonistas do processo produtivo; como também o barateamento das mercadorias consumidas (força de trabalho e matérias primas) e produzidas (produtos). É neste sentido que o progresso técnico representado neste caso, pela introdução da maquinaria no processo produtivo, longe de ser um avanço inexorável ao processo evolutivo da humanidade (PEREZ, FREEMAN, 1988. PEREZ, 2002) responde especificamente a "vetor" resultante da luta de classes.

Ao considerar a problemática do desenvolvimento tecnológico no capitalismo, Mandel (1985) argumenta que as escolhas sobre determinadas técnicas em detrimento de outras são feitas por razões de lucratividade pelos ramos específicos da indústria, ou melhor, pelas empresas líderes naqueles ramos. Nesse sentido, as teses que argumentam sobre a preponderância da ciência e da técnica como forças produtivas nas sociedades contemporâneas são equivocadas. O conhecimento social gerado pelo progresso científico tem seu objetivo restringido pela lógica do capital ao mesmo tempo em que ocorre a apropriação desigual dos resultados e benefícios da ciência e da tecnologia, bem como do aumento da produtividade do trabalho social (ANTUNES, 2000; 2006). No contexto da reestruturação produtiva a partir da década de 1980, com a introdução de inovações técnicas e/ou organizacionais, se impõe para as empresas a necessidade de encontrar uma força de trabalho mais qualificada e multifuncional que deverá ser explorada de forma mais intensa e sofisticada pelo capital.

A extração da mais valia relativa neste sentido possui o intuito de diminuir o tempo de trabalho necessário e o aumento do tempo de trabalho excedente, com o conseqüentemente barateamento tanto das mercadorias e conseqüentemente da força de trabalho consumida no processo produtivo. De principal fator de força motriz do processo 
produtivo a maquinaria converte o trabalhador em seu apêndice indispensável. Após romper com os limites a ela antepostos, a maquinaria aumenta seu potencial de consumo de trabalho vivo ao dar condições para que novas capacidades de trabalho (antes não exploradas) possam "democraticamente" ser consumidas no processo produtivo - mulheres e crianças. Ao converter o ofício produtivo dos trabalhadores a simples gestos automáticos e repetitivos, permite dada a "simplicidade" de tais gestos, que o capitalista economize empregando forças de trabalho dóceis, abundantes e baratas. Neste estágio de exploração a destreza ou a familiaridade com a tarefa, para não se referir mais ao ofício, se tornam indiferentes, possibilitando ao capitalista maior poder de barganha na manutenção dos baixos salários e maior controle dos trabalhadores.

É da passagem da manufatura para maquinaria que verificamos a metamorfose consolidada e definitiva do capital em sua essência, de uma subsunção formal para uma subsunção real do trabalho ao capital (PREVIALLI, 2005). É a partir deste estágio que a ofensiva do capital sobre o trabalho adquire sua natureza pronta e acabada, a qual dispõe dos mecanismos necessários para a real diminuição do tempo de trabalho necessário e aumento do tempo excedente de produção. Agora, a ciência como tecnologia, aplicada ao processo de produção, demonstra todo seu caráter de classe, sendo o seu desenvolvimento pautado na extração de sobrevalor do trabalho humano, seja por meio do controle e expropriação do saber fazer, seja como meio do empobrecimento do sujeito que realiza trabalho. É neste estágio da sociabilidade regida pelo capital que Marx observa e ressalta o modo de produção especificamente capitalista, em que o valor de troca da mercadoria se sobrepõe ao seu valor de uso.

Cabe, porém a seguinte ressalva a cerca da transformação da subordinação formal a real do trabalho. Tal transformação entre estas duas formas de ser da produção capitalista não se excluem, mas pelo contrário se complementam. O que queremos aqui dizer é que, por mais que a subordinação real do trabalho revolucione a sua anterior, as manifestações da primeira estão contidas na segunda. O processo de subordinação real do trabalho conserva as ofensivas outrora conquistadas no processo de extração de mais valor, aperfeiçoando-as. Portanto temos ainda presentes o trabalhador coletivo da cooperação simples, o qual se pode inferir que o mesmo foi adaptado ao orquestramento da maquinaria em seu conjunto, ou seja, o autômato central e seus periféricos. Como também se manteve a divisão parcelar do trabalho introduzido pela manufatura.

É sobre o caráter indiferente da maquinaria em relação ao trabalhador que a manuseia em que se verifica a necessidade do controle ainda maior na fábrica. A disciplina de caserna como frisa Marx, nivela todos os portadores de capacidade de trabalho a um denominador comum, indiferente à idade ou sexo, necessário à valorização do capital. Essa vantagem comparativa só foi conseguida adequando-se e aperfeiçoando-se todos os autômatos de tal forma que a destreza e/ou conhecimento do processo produtivo fossem convertidos em simples gestos automatizados, rotinizados e estranhos aos conteúdos, porém sob constante controle e vigilância da gerência.

Segundo Braverman (1977), a gerência busca assegurar o seu controle, primeiro determinando as tarefas individuais e depois através da direção de todo o dia de trabalho para a certeza de que as tarefas serão cumpridas. A legitimidade da gerência se assenta no discurso da aplicação científica e imparcial dos princípios de eficiência. No entanto, o autor mostrou em seu trabalho, a despeito da retórica da eficiência científica, como o taylorismo se torna um projeto ideológico de dominação com o objetivo de assegurar a subordinação real do trabalho. Assim, o controle do trabalho se faz necessário porque ele garante o caminho da produtividade, inibindo os tempos improdutivos para o capital, apropriando-se do conhecimento do trabalhador e, portanto, garantindo a sua acumulação. 
É exatamente porque o capital não pode eliminar o trabalho vivo do processo de criação de valores que ele necessita aumentar a utilização e a produtividade do trabalho. A condição para que o sistema produtivo do capital se mantenha é a integração entre trabalho vivo e trabalho morto.

Braverman (1977) argumenta que o meio de impedir o controle do processo de trabalho pelos trabalhadores foi através da dissociação entre concepção e execução, isto é, entre trabalho intelectual e trabalho manual. A consequiência imediata dessa dissociação foi a desqualificação do trabalhador, dada a nova natureza que o trabalho adquiriu, reduzido a tarefas simplificadas e rotineiras, cada vez mais especializadas e sem conteúdo. O taylorismo-fordismo configurou-se na expropriação do saber operário e a sua concentração nas mãos da gerência administrativa. Esta, por sua vez, racionalizou a produção, estabelecendo "o melhor caminho" para a realização do trabalho.

O espaço interno da fábrica foi reorganizado, fixando o trabalhador em um ponto, o posto de trabalho, realizando os mesmos movimentos e utilizando as mesmas ferramentas. Os trabalhadores perderam, não somente o controle e a capacidade de decisão que possuíam sobre o processo de trabalho, mas também passaram a ser colocados sob o domínio de uma estrutura administrativa fortemente hierarquizada (BRAVERMAN, 1977), o que possibilitou, juntamente com outros fatores que veremos a seguir, a acumulação do capital. 1960)

\section{1 - O taylorismo-fordismo como Forma de Acumulação do Capital (1930 -}

O termo Regime Fordista foi adotado por Aglietta (2000) e Boyer (2000) para explicar o modo de produção capitalista, particularmente durante o período de crescimento após a Segunda Guerra Mundial. Os autores desenvolveram a "teoria da regulação" do capitalismo, de acordo com a qual a produção fordista é a base de um modo de regulação e reprodução das relações sociais de produção, distribuição e consumo. Assim, o modo de regulação fordista constitui um regime de acumulação que proporciona estabilidade e dinamismo à sociedade capitalista no pós guerra.

De acordo com Aglietta (2000), o regime de acumulação proporcionou à superação das barreiras para uma acumulação sustentada do capital, as quais repousam de um lado, na resistência dos trabalhadores à tentativa de aumentar a produtividade e, de outro lado, nas desproporções entre produção e consumo. Essas barreiras foram superadas pela instituição de uma negociação coletiva, envolvendo capital e trabalho e Estado, a qual procurou promover e assegurar, ao mesmo tempo, a acomodação dos trabalhadores ao processo de intensificação do trabalho e o crescimento do mercado para o consumo com a intermediação de uma política macroeconômica, corporativa, que regulava produção, demanda e distribuição.

Nesse regime de crescimento, a inflação dos produtos e o mercado de trabalho possuíam uma dupla função, quais sejam: (a) como síntese das tensões econômicas e (b) como mecanismo de regulação dessas crises (AGLIETTA, 2000). Assim, ela era anticíclica e assegurava alguma combinação entre ganhos de produtividade e aumentos reais de salários, via a negociação coletiva, que se tornou a instituição central nessa era do capitalismo até o choque do preço do petróleo (Aglietta, 2000).

Para Aglieta (2000) e Boyer (2000), o fordismo é intrinsecamente relacionado ao Estado keynesiano, sendo a crise dos anos 70 a quebra desse modo de acumulação, cujos fatores principais repousam sobre os seguintes elementos:

(a) os limites na manufatura; 
(b) o crescimento da resistência da classe trabalhadora à intensificação e ao controle;

(c) o baixo crescimento da produtividade;

(d) a redução dos lucros.

Esses elementos provocaram um processo de estagnação inflacionaria e desemprego, levando à crise e declínio do regime fordista. De acordo com Boyer (2000), “(...) os anos 90 têm visto a emergência de um novo candidato à sucessão do fordismo, sob a liderança do setor financeiro(...)” (Boyer, 2000: 03).

É importante ressaltar a contribuição dos autores da Escola de Regulação à compreensão do taylorismo-foridismo enquanto uma via de acumulação do capital, no qual a combinação de mecanismos reguladores possibilitou o crescimento e a relativa estabilidade do modo de produção capitalista. No entanto, é igualmente importante ressaltar que o regime taylorista-fordista de acumulação do capital deve ser entendido no contexto da dinâmica das relações de classe de cada país onde se desenvolveu e no âmbito da divisão internacional do trabalho ${ }^{\text {iv }}$. O regime de acumulação do capital anterior ao taylorista-fordista era de característica essencialmente extensiva, fundado na extração da mais-valia absoluta, isto é, na extração do trabalho excedente por meio do prolongamento da jornada de trabalho. Com o desenvolvimento do novo regime, o processo de acumulação passa a ser de característica essencialmente intensiva, fundado sob a formação da mais-valia relativa obtida através do desenvolvimento técnico (BIHR,1998).

De acordo com Bihr (1998), há uma tendência do processo de acumulação capitalista assumir um caráter essencialmente intensivo no desenvolvimento das forças produtivas da sociedade. Entretanto essa tendência, por sua vez, acaba por provocar uma crise de superprodução na sociedade na medida em que o capital desconsidera as diferenças entre os ramos industriais ${ }^{v}$ e a capacidade total de consumo da sociedade, tal como ocorreu ao longo da década de 1920, provocando a crise que se manifestou totalmente nos anos 1930. É importante destacar os elementos fundamentais para o estabelecimento do novo regime de acumulação taylorista-fordista durante as décadas de 1920 e 1930.

O primeiro diz respeito às divergências dentro do próprio movimento sindical. Bihr (1998) argumenta que a trajetória do movimento operário, mais precisamente o êxito da vertente reformista, social-democrata, em detrimento da vertente revolucionária é que possibilitou a formação de um "compromisso de classes" intermediado e regulado pelo Estado, implicando no desenvolvimento do regime taylorista-fordista de acumulação do capital. O autor destaca que o regime não acabou com a luta de classes, mas circunscreveua aos limites do compromisso que implicava na aceitação, por parte da classe trabalhadora, do conjunto de transformações na organização do trabalho e da forma de desenvolvimento capitalista em troca da garantia de seus interesses de classe mais imediatos, relativos à sua seguridade social. O regime social-democrata do movimento operário começou a se destacar, adotando o discurso da legalidade e do desenvolvimentismo do Estado-Nação, sendo impregnado pelo "fetichismo do Estado", num período que as lutas trabalhistas pela emancipação do capital estavam sendo derrotadas em vários países.

Nesse sentido, o movimento operário começou a renunciar a luta revolucionária, ao mesmo tempo em que foi aceitando discutir a dominação capitalista nos termos de um compromisso. Cumpre ainda destacar que nesse momento, a própria composição do proletariado estava se transformando. $\mathrm{O}$ operário de ofício, hegemônico até a eclosão da primeira guerra mundial e que impunha ao movimento operário suas características revolucionárias estava desaparecendo e dando lugar a um novo perfil de trabalhador, o "operário-massa", moldado dentro de o trabalho parcelar e desprovido de conteúdo da 
produção em massa e que se tornou a nova força de trabalho hegemônica do compromisso taylorista-fordista (BIHR, 1998).

$\mathrm{O}$ segundo refere-se à classe burguesa, esta se viu obrigada a renunciar ao liberalismo de classe para aceitar as bases do compromisso e as políticas intervencionistas do Estado. Com o fracasso dos governos liberais em conter a crise ao longo das décadas de 20 e 30, vários intelectuais e políticos passaram a considerar o intervencionismo estatal como forma de regular a economia e disciplinar as relações de trabalho sob mecanismos mais eficientes (BIHR, 1998). A Grande Depressão dos anos 1920 e 1930 demonstrou às classes capitalistas que o regime de acumulação fundamentado em princípios tayloristasfordistas de organização do processo produtivo somente seria viável se houvesse uma profunda mudança na relação salarial, envolvendo todas as condições econômicas, sociais e político-jurídicas, visando à uma nova forma de regulação. De acordo com Bihr (1998), essa nova forma formalizou-se em um compromisso estabelecido entre trabalho e capital, permitindo a acumulação deste último.

O Estado passou a intervir na economia, exercendo a função de regulador das relações entre capital e trabalho e inseriu uma série de reivindicações trabalhistas, introduzindo a negociação coletiva entre trabalhadores e empresários, através do reconhecimento dos sindicatos como representantes legítimos dos trabalhadores. Um dos pontos fundamentais do compromisso de classes relacionava-se ao fato de que o incremento da produtividade do trabalho e os aumentos salariais deveriam ser ajustados de forma a não permitir crises de subconsumo (BOYER, 1988; BIHR, 1998).

Ademais, a produção em massa em máquinas dedicadas, gerando uma demanda crescente por novos produtos e serviços, promovia novas oportunidades de emprego, eliminando um provável aumento do desemprego provocado pelos ganhos de produtividade (Boyer, 1988; Bihr, 1998). Outro elemento importante foi a instituição dos salários indiretos ou benefícios sociais relacionados ao seguro desemprego, seguro saúde, previdência social, auxílio à educação, financiados através de impostos obrigatórios, visando permitir a reprodução da força de trabalho e a garantia do consumo de mercadorias (BIHR, 1998). Dessa forma, associou-se a elevação da produtividade a ganhos salariais, possibilitando-se uma maior distribuição de ganhos de produtividade, assegurando-se a demanda e garantindo-se um relativo equilíbrio econômico e social o que resultou em um período de grande expansão do capitalismo até o início dos anos 1970, quando começou a apresentar sinais de crise (BOYER, 1988).

Assim, o regime taylorista-fordista significou, por um lado, uma nova forma de organização do trabalho no interior das fábricas. Por outro lado, em termos mais gerais, significou a consolidação de um regime de acumulação do capitalismo na medida em que a reorganização do processo produtivo envolveu também um conjunto de mudanças sociais e ideológicas. Essa via de organização da produção e do trabalho, adotado primeiramente na indústria automotiva, um dos setores de maior dinamismo na economia mundial, tornou-se, após a Segunda Guerra Mundial, o meio pelo qual o capitalismo readquiriu suas forças, emergindo da crise dos anos 1920 e 1930 (PREVITALLI, 2002; LUCENA, 2004).

O regime atingiu maior nível de desenvolvimento durante a década de 1950. Nesse período, já se encontrava superada a fase de reconstrução da capacidade produtiva do pósguerra e consolidava-se o padrão de produção e consumo com base nas vantagens das economias de escala e na utilização de uma força de trabalho altamente especializada. Na segunda metade da década de 60 , a estabilidade e hegemonia do regime taylorista-fordista começaram a ser questionadas. Nesse contexto, intensificou-se um processo de expansão e difusão das práticas de organização e controle do trabalho nos países do Terceiro Mundo, desencadeado pela expansão multinacional de empresas norte-americanas e européias que 
viram possibilidades de crescimento além de seu mercado de origem. Esse processo implicou na ampliação do comércio internacional e em uma nova divisão internacional do trabalho, baseada na troca de matérias-primas e produtos manufaturados entre os países.

Os limites da organização taylorista-fordista relacionam-se à sua própria lógica uma vez que o parcelamento do trabalho em um grande número de tarefas especializadas implicou no aumento do tempo em que o produto é apenas transportado e não transformado centrais e os países periféricos (CORIAT 1988 e 1993). Dessa forma, os tempos mortos eliminados na etapa anterior da produção regressavam na etapa seguinte. Ademais os diferentes tempos de fabricação de cada peça não permitiam uma perfeita integração entre os postos de trabalho, contribuindo também para o aumento de tempos improdutivos para o capital. Na tentativa de solucionar esses problemas e obter índices maiores de produtividade, as empresas intensificaram o processo de trabalho, implicando no crescimento da resistência dos trabalhadores aos métodos tayloristas-fordistas de organização do processo de trabalho (BEYNON, 1984, FAIRBROTHER, 2000).

\section{2 - O Controle taylorista-fordista do Trabalho e a Formação do "Novo Trabalhador": desqualificação e precarização.}

Nas duas primeiras décadas do século XX as empresas iniciaram sua transformação para fabricação de produtos em grandes quantidades, a produção em massa. Como observado por Gramsci (1984) no período inicial da formação do fordismo, todos os aspectos da vida social, sexual e religiosa começaram a ser racionalizados, de forma coercitiva, através do estabelecimento de novos valores morais. Nas palavras do autor:

" (...) sob um novo ideário ideológico, desenvolveu-se um novo tipo de indivíduo social (...). Na América, a racionalização determinou a necessidade de elaborar um novo tipo humano, conforme ao novo tipo de trabalho e de produção: até agora esta elaboração acha-se na fase inicial e por isso (aparentemente) idílica" (GRAMSCI, 1984:382).

É nesse sentido que Gramsci (1984) analisou as iniciativas puritanas de Ford, relacionadas à humanização do trabalhador. No ambiente fabril, não havia mais espaço para humanização na medida em que o processo produtivo estava desprovido de conteúdo e de sentido para o trabalhador. Portanto,

“(...) as iniciativas puritanas só têm o objetivo de conservar, fora do trabalho, um determinado equilíbrio psicológico que impeça o colapso fisiológico do trabalhador, premido pelo novo método de produção. Este equilíbrio só pode ser externo e mecânico, mas poderá se tornar interno se for proposto pelo próprio trabalhador (...); se for imposto por uma nova forma de sociedade, com meios apropriados $e$ originais" (GRAMSCI, 1984: 397).

Nesse contexto foi desenvolvida uma nova parcela hegemônica da classe trabalhadora, o operário-massa. Essa denominação ocorreu devido à sua concentração tanto na fábrica quanto fora delas. O processo de concentração, se por um lado implicou na perda da identidade anterior, por outro lado, possibilitou a formação de uma nova identidade sociocultural e de uma nova consciência de classe (BIHR, 1998). O trabalhador pré-fordista possuía ainda certa autonomia em relação ao capital, tanto no trabalho quanto fora dele. Já o operário-massa perde essa autonomia, tornando-se parte de um sistema mecânico de produção e dependendo totalmente do seu salário e do mercado capitalista para a reprodução de sua força de trabalho. Nos Estados Unidos, berço da organização fordista, aproximadamente quatro quintos da população trabalhava por conta própria no 
início do século XIX. Em 1870, esse índice foi reduzido para aproximadamente um terço da população. Em 1940 não constituía mais que um quinto da população, chegando a aproximadamente um décimo em 1970 (BRAVERMAN, 1977).

Babson (1995) afirma que a mecanização e padronização foram sinônimas do sistema fordista tornando-se o modelo da produção em massa e expandindo-se mundialmente. Entretanto, para o autor, nenhum outro país aplicou tão ao extremo os princípios fordistas de controle do processo de trabalho quanto os Estados Unidos. Somente no país é que havia uma massa de imigrantes disponível para o trabalho em massa. Ademais, comparando-se com os mercados europeus, pequenos e dominados pelas elites, no país havia um imenso mercado que crescia pela imigração e pela expansão continental e requeria economias de escala que usariam máquinas especializadas e trabalhadores estreitamente treinados em grande quantidade. Segundo o autor, o crescimento norte-americano no final do século XIX e início da década de 1920 foi possível, por um lado, através da utilização de imigrantes famintos e trabalhadores rurais dispostos a trabalhar por longas horas e, por outro lado, pela intimidação dos movimentos de organização da classe trabalhadora.

Babson (1995) destaca quatro elementos fundamentais que moldaram o regime fordista tal como ele se tornou predominante:

(a) o crescimento da propaganda e da promoção de uma cultura conformista consumista que assegurou um mercado de massa para a produção em massa;

(b) o crescimento da intervenção do Estado para estabilizar o sistema através de programas sociais e gastos públicos que suportou o consumo de massa durante os períodos de crise econômica;

(c) o crescimento de um novo tipo de movimento sindical. O taylorismo-fordismo havia destruído muito dos bastiões da produção artesanal no setor industrial, destruindo também as bases da organização desses trabalhadores. No entanto, fazendo isso, ajudou a preparar a base para uma mais abrangente forma de sindicato industrial;

(d) o crescimento da economia norte-americana após a Segunda Grande Guerra proporcionou a expansão do sistema taylorista-fordista internamente. As Três Grandes Empresas (Ford, Chrysler e General Motors) agiram no sentido de estender a produção, até então concentrada em Dearborn, Detroit and Flint, para os subúrbios e áreas rurais, onde os mercados estavam em crescimento e o movimento sindical era fraco.

Esse processo deu início aos primeiros movimentos de realocação geográfica do setor no país. Ao mesmo tempo houve a expansão dessas empresas para os países do continente europeu, inserindo-os no contexto do processo de racionalização tayloristafordista. Apesar do movimento de racionalização, implicando na desqualificação do conteúdo das tarefas no trabalho parcelar, as habilidades e o ritmo do trabalho ainda dependiam do trabalhador, posto que o trabalho vivo permanecia como a base do processo produtivo, levando ao desenvolvimento de um conjunto de práticas cotidianas no chão de fábrica, envolvendo aceitação e resistência ao controle do trabalho (BURAWOY, 1978).

Portanto, a necessidade da constante reorganização do processo produtivo ocorre justamente como necessidade de combater a resistência dos trabalhadores ao controle e à racionalização. A primeira tentativa da Ford para combater a resistência dos trabalhadores à racionalização envolveu a criação de um novo skill-wage no final de 1913 com o objetivo motivar a força de trabalho, mas os resultados não foram satisfatórios. Em 1914 foi introduzido o pagamento de cinco dólares/dia por oito horas de trabalho que associava pagamento de salários mais altos à uma rígida supervisão. A introdução dessa política consistiu no corte de horas de trabalho, ao mesmo tempo em que dobrou os salários, na forma de cotas, mas somente para aqueles que se conformassem com o padrão de 
comportamento imposto pela companhia. A avaliação, levada a cabo pelo departamento de sociologia da empresa, incluía testes sobre a conduta moral, religiosa e social dos trabalhadores, o que contribuiu para desenvolver os valores americanos que passaram a constituir a ideologia do "American Way Life" (MILKMAN, 1997).

O tipo de movimento sindical que marcou a indústria automotiva, particularmente nos Estados Unidos após $1937^{\mathrm{vi}}$, objetivou regular, mais que derrubar o novo regime de acumulação do capital (BABSON, 1995; MILKMAN, 1997). Cumpre ressaltar que a forma como foi sendo constituída a estrutura industrial, fundada na grande empresa com integração vertical das atividades, encorajou esse tipo de sindicalismo, assim como a negociação coletiva. Embora o novo movimento sindical da era taylorista-fordista tenha deixado intacto o sistema de classificação das tarefas e qualificações desenvolvidos pela gerência administrativa, ele forçou a implementação de uma redução nas diferenças salariais entre as tarefas e institucionalizou a senioridade como princípio básico para demissões e transferências de tarefas (BABSON, 1995; MILKMAN, 1997). A união dos trabalhadores resultou em um conjunto de direitos no local de trabalho, envolvendo a regulação e padronização dos critérios de demissões, promoções, transferências, bem como a classificação das tarefas e as formas de pagamento. Nesse contexto, as greves foram se tornando menos freqüentes e, quando ocorriam, relacionavam-se à aumentos salariais e de benefícios. "(...) após décadas o job-control deixou a gerência no comando das decisões estratégicas e sobre as operações do cotidiano" (BABSON, 1995:11).

De acordo com Milkman (1997):

(...) o movimento sindical objetivou obter melhorias em termos puramente econômicos, sob os quais os membros concordavam em se submeter. Para muitos trabalhadores, esse era o único incentivo para o retorno aos portões da fábrica dia após dia” (MILKMAN, 1997:25).

Durante todo o período pós-guerra, os trabalhadores da indústria automotiva obtiveram contínuo aumento salarial e melhoria de benefícios em relação aos demais setores da economia, modo pelo qual se tornaram "os blue collar aristocrats" da classe trabalhadora (Milkman, 1997:25). Deve-se ressaltar que a política de reconhecimento dos sindicatos ocorreu no contexto da recessão dos anos 1930 e do crescimento do novo movimento sindical. Na verdade, o reconhecimento do movimento sindical era uma forma de internalizar o conflito entre capital e trabalho e adequá-lo aos novos contornos de uma negociação política, com a intermediação do Estado (Clarke, 1994). De acordo com o autor:

"(...) os sindicatos tornavam-se despolitizados, reduzidos à instituições seccionais representativas apenas de interesses econômicos, negociando coletivamente dentro de uma dada estrutura e representando politicamente somente os interesses de grupos dentro de um sistema dado. Tinham se subordinado não aos interesses da classe trabalhadora, mas do capitalismo" (Clarke, 1994:25).

Portanto, as relações de classe e a luta pelo controle social do trabalho implicaram no desenvolvimento de um conjunto de relações no nível macroeconômico que propiciou a formação do regime taylorista-fordista de acumulação. Esse regime envolveu, com variações dependendo das condições históricas, sociais e culturais onde foi vivenciado, um conjunto de práticas de político-institucionais e de controle do trabalho, bem como de formas de intervenção e resistência classe trabalhadora que asseguraram a produção em 
massa e a acumulação do capital até apresentar sinais de esgotamento durante a segunda metade da década de 1970.

Como resposta a crise, o capital iniciou, ao longo das décadas de 1980 e 1990, um amplo processo de reestruturação que envolveu a introdução de inovações técnicas e/ou organizacionais no processo de trabalho, visando assegurar o controle sobre o mesmo. A expressão mais evidente dessas mudanças foi o advento das formas toyotistas ou do chamado "modelo japonês" de organização do processo produtivo.

\section{2 - A Reestruturação Produtiva: trabalho e qualificação}

A década de 1980 foi marcada por um amplo processo de adaptação e imitação dos métodos japoneses pelas empresas ocidentais. O chamado modelo japonês (Hirata, 1993) ou toyotismo (ANTUNES, 2000; ALVES, 2000), cujos elementos proporcionam maior controle sobre o fluxo do processo de trabalho, sobre o processo de trabalho sobre o movimento sindical, emergiu para as empresas ocidentais como um "receituário" a fim de promover a recuperação da crise do capitalismo. Nesse momento as palavras de ordem nas empresas passaram a ser qualidade e flexibilidade.

Inicialmente as empresas adotaram algumas técnicas isoladas e seletivas, voltadas para o controle do processo de trabalho, visando a otimização do processo de produção, redução dos chamados desperdícios e maior envolvimento do trabalhador. As técnicas mais introduzidas pelas empresas foram: os Grupos de Controle da Qualidade (CCQs), os gráficos de Controle Estatístico de Processo (CEP) e o Just-in-Time (JIT) interno (Salerno, 1993). Cumpre dizer, que com o fracasso de muitos desses programas, particularmente os que visavam o envolvimento do trabalhador, as empresas começaram a adotar uma prática mais sistêmica no processo de reestruturação (HILL, 1991; PREVITALLI, 1996 e 2000).

Na década de 1990, as empresas voltaram-se para a adoção de uma abordagem mais sistêmica das práticas toyotistas, envolvendo o Total Quality Control (TQM) e o JIT externo, isto é, com as empresas fornecedoras (HILL, 1991 ${ }^{\text {vii; }}$ BEYNON, 1998; PREVITALLI, 1996 E 2000). Nesse contexto a nova palavra de ordem passou a ser flexibilidade. As empresas buscaram também aumentar os investimentos em inovação de produto e processo, os quais se tornaram áreas importantes para a garantia da competitividade.

No Brasil após 1994, com o Plano Real, sob o governo Fernando Henrique Cardoso, os Programas de Qualidade Total, sistema just-in-time/kan-ban e, principalmente, os bônus de salários vinculados à lucratividade e obtenção de metas de qualidade e produtividade, encontraram um cenário macroeconômico propício para a sua expansão. Ocorre uma forte intensificação da terceirização/subcontratação, bem como a instauração de novos programas organizacionais, que procuram captar a subjetividade dos trabalhadores através do desenvolvimento de uma nova base técnica da produção, com a utilização, em vários ramos produtivos, da automação microeletrônica na produção e das novas tecnologias de informação. As empresas passaram a investir em treinamento no local de trabalho de forma a propiciar um processo contínuo de agregação de informações e capacidades necessárias para formar trabalhadores multifuncionais e polivalentes (Previtalli, 2002). Para o capital passa a ser um diferencial na concorrência intercapitalista obter o comprometimento e a participação dos trabalhadores de chão de fábrica na forma de sugestões e projetos sobre o sistema produtivo no dia-a-dia no local de trabalho.

Segundo a literatura (PREVITALLI, 2006, FARIA e PREVITALLI, 2008) um dos programas mais enfatizados na garantia do aprendizado contínuo, tendo como objetivo assegurar o comprometimento dos trabalhadores foi a gestão participativa. Nesse sentido, 
as empresas passaram a investir em novos meios de comunicação com o trabalhador, como o circuito interno de TV e os jornais oficiais do grupo nos quais são veiculadas notícias positivas sobre o grupo e a empresa. Tem inicio um monitoramento bastante específico das tarefas e ações dos trabalhadores em função do seu próprio desempenho (metas individuais) e do desempenho da equipe. Ao mesmo tempo, a gerência começa a enfatizar um conjunto de qualificações e habilidades dos trabalhadores do chão-de-fábrica que até então não eram significativos. Pesquisa realizada por Previtalli (2006) mostrou que quesitos subjetivos tais como: saber trabalhar em grupos, ter iniciativa, ser participativo, ser responsável passaram a ter prioridade em detrimento da experiência profissional.

Essas novas qualificações e habilidades fazem parte de um conjunto de ferramentas pelas quais o capital procura captar a subjetividade dos trabalhadores, de forma a ser construído um novo padrão de organização e controle do trabalho que busca assegurar a disciplina e o comprometimento do trabalhador no local de trabalho e também fora dele.

\section{Considerações Finais}

O processo de reestruturação produtiva das empresas nada mais é que a reestruturação do capital, visando assegurar sua expansão e acumulação. À medida que esse processo avança, envolvendo mudanças tecnológicas e organizacionais, impõe-se para as empresas a necessidade de encontrar uma força de trabalho mais complexa, mais heterogênea e mais multifuncional que deverá ser explorada de forma mais intensa e sofisticada pelo capital.

A reestruturação produtiva do capital envolve ainda um novo quadro político e institucional, de base liberal, o neoliberalismo, inaugurado com o governo conservador de Thatcher na Gra-Bretanha em 1979. Cada vez mais as empresas beneficiam-se do novo quadro neoliberal para reorganizar as modalidades de sua internacionalização e para modificar suas relações com a classe trabalhadora via intensificação do processo de flexibilização envolvendo práticas de gestão de recursos humanos, bem da terceirização e subcontratação e do trabalho temporário.

Nesse novo contexto, as mudanças tecnológicas e/ou organizacionais associadas ao toyotismo são apresentadas como as mais eficientes e racionais para o desempenho do processo produtivo. A difusão das novas tecnologias associada às novas práticas de gestão de recursos humanos estariam possibilitando a recuperação da inteligência do trabalhador no local de trabalho, particularmente devido à introdução das células de produção e dos times ou grupos de trabalho ${ }^{\text {viii }}$. Entretanto, pesquisas sobre a realidade dos locais de trabalho têm evidenciado que há uma limitada reintegração entre concepção e execução através dos grupos de trabalho, havendo uma autonomia meramente nominal dos times de trabalho que devem continuamente aumentar a produtividade.

Portanto, a introdução e difusão de inovações técnicas e/ou organizacionais no processo produtivo estão circunscritas à lógica do capital, tendo como um de seus objetivos fundamentais a garantia da produtividade e da lucratividade via controle sobre o processo de trabalho.

Cumpre dizer ainda que as estratégias das empresas impuseram aos trabalhadores um processo crescente de intensificação do trabalho. Com o avanço da reestruturação produtiva do capital ao longo dos anos 1990, o combate e a crítica às políticas de reestruturação adotadas pelas empresas tenderam a dar lugar a um processo de adaptação e adequação do movimento sindical a nova ordem do capital. As estratégias de resistência da classe trabalhadora passaram a priorizar a negociação com as empresas, visando à defesa e à manutenção do emprego. Se há ainda um quadro potencial para o conflito, o crescimento 
do sindicalismo de negócios sugere que as formas de oposição ainda são fracas e periféricas.

\section{Bibliografia}

AGLIETTA, M. A Comment and Some Tricky Questions. University of Paris X - Nanterre and CPEII (Centre d'Etudes Prospectives d'Informations internationales) (mimeo). 2000.

ALVES, G. O Novo (e Precário) Mundo do Trabalho: reestruturação produtiva e crise do sindicalismo. São Paulo: Boitempo. 2000.

ANTUNES, R. Os Sentidos do Trabalho. São Paulo: Boitempo. 2000.

ATKINSON, J. "The Changing Corporation", IN: CLUTTERBURCK (Ed). New Patterns of the Work. Aldershot: Gower. 1985.

BABSON, S "Lean Production and Labor: empowerment and explotation", IN: BABSON, S. (Ed). Lean Work: empowerment and explotation in the global industry. Detroit:Wayne State University Press. 1995.

BALIBAR, E. "Sur les concepts fondamentaux du Matérialisme Historique", IN: Althusser, L. et al. Lire le Capital. Paris: Ptite Collection Maspero. N. 31. 1973.

BEYNON, H. "Changes at Work". IN: Working Paper N. 19. University of Manchester. International Centre for Labour Studies. 1993.

BIHR, A Da Grande Noite à Alternativa: o movimento operário europeu em crise. São Paulo: Boitempo. 1998.

BOYER, R. Is a Finance Led Growth Regime a Viable Alternative to Fordism? CEPREMAP, CNRS, EHESS. Paris/France. (mimeo). 2000.

BRAVERMAN, H. Trabalho e Capital Monopolista. Rio de Janeiro: Zahar. 1977.

BRESCIANI, L. P. O Contrato da Mudança: a inovação e os papéis dos trabalhadores na indústria brasileira de caminhões. Tese de Doutorado. Campinas: IG/UNICAMP. 2001.

BURAWOY, M. "Toward a Marxist theory of the labour process: Braverman and beyond”. In: Politics and Society. v.8, n³-4, 1978. pp 247-312.

CORIAT, B “Ohno e a Escola Japonesa de Gestão da Produção: um ponto de vista de conjunto", IN: HIRATA, h (Org). O Modelo Japonês: automatização, novas formas de organização e de relações de trabalho. São Paulo: Edusp. 1993.

Revista HISTEDBR On-line, Campinas, n. Especial, p.92-111, mai.2009 - ISSN: 1676-2584 
COUTINHO, L \& FERRAZ, J. C. (Coord). Estudo da Competitividade da Indústria Brasileira. Campinas:Papirus. 1994.

COX. K. R. "Introduction: globalization and Its Politics in Question", IN: COX. K. R (Ed). Spaces of Globalization: reasserting the power of the local. London: Guilford. 1997.

FAIRBROTHER, P. "British Trade Unions Facing the Future”, IN: Capital \& Class. 2000.

FREEMAN, C. \& PEREZ, C. "Structural Crises of Adjustment, Business Cycles and Investiment Behaviour", IN: DOSI et all (Eds). Technical Change and Economic Theory.. London: Pinter Publishes. 1988.

GALVÃO. A. “Os Novos Desafios do Sindicalismo no Governo Lula”, IN: Outubro. N.14 2006.

GEREFFI. G. Global Commodity Chains: News Forms of Coordiantion and Control Among Nations and International Industries, IN: Competition \& Change. Vol. 4. 1996.

GITAHY, L \& BRESCIANI, L. P "Reestruturação Produtiva e Trabalho na Indústria Automobilística Brasileira. Texto para Discussão N. 24. Campinas: DPCT/IG/UNICAMP. Campinas. 1998.

GITAHY, L et al. Relações Interfirmas e Gestão de Recursos Humanos na Cadeia Produtiva de Autopeças. Relatório de Pesquisa: Projeto "Reestruturação Produtiva, Trabalho e Educação. Campinas. FINEP/CEDES/CNPq. 1997.

GITAHY, L. "Na Direção de um Novo Paradigma de Organização Industrial?”. Trabalho apresentado no XVI Encontro Nacional da ANPOCS. Caxambu. Outubro. 1992.

GOUNET, T. "La Stratégie Japonaise de Iorissen”. Études Marxistes. N 37. Mai-Jun. Bruxelas. 1997.

GRAMSCI, A “Americanismo e Fordismo", IN: Maquiavel, a Política e o Estado Moderno. Civilização Brasileira. Rio de Janeiro. 1984.

HARVEY, D Condição Pós-Moderna. São Paulo: Edições Loyola. 1992.

HIRATA, H “Introdução", IN: HIRATA, H (Org). Sobre o “Modelo” Japonês. São Paulo: Edusp. 1993.

HOFFMAN, K. \& KAPLINSK, R. Driving Force: the global restructuring of technology, labor and investment in the automobile and components industries. Westview. Boulder. 1988. 
LEITE, M. P. "Modernização Tecnológica e Relações Industriais no Brasil: o quadro atual", in GITAHY, L. (Org.) Reestructuración Produtiva, Trabajo y Educación en América Latina. Campinas. IE/UNICAMP. Buenos Aires. RECIID - CONEP. 1994.

LUCENA, C. Tempos de Destruição: educação, trabalho e indústria do petróleo no Brasil. Autores Associados/EDUSP. 2004.

MARX, K. O Capital. Vol.1. São Paulo: Nova Cultural. 1988.

MARX, K. 2004.

McILROY, J. "The Enduring Alliance? Trade Unions and the Making of New Labour, 1994 - 1997”, IN: British Journal of Industrial Relations. Vol. 36, N. 4. 1998.

MEIKSINS, P (1994) "Labor and Monopoly Capital for the 1990s: a review and critique of the labor process debate", IN: Monthly Review, Vol 46, N. 6. 1994.

PIORE, M. \& SABEL, C. The Second Industrial Divide - possibilities for prosperity. Basic Books. New York. 1984.

POLLERT. "Team Work on the Assembly Line: contradiction and the dynamics of union resilience", IN: ACKERS, et al. (Ed). The New Workplace and Trade Unionism. London: Routledge.1996.

PREVITALLI, F. S. "Controle e Resistência na Organização do Trabalho: o caso de uma empresa montadora nos anos 90". Tese de doutorado. Campinas: UNICAMP/IFCH. 2002.

PREVITALLI, F. S. "Reestruturação Produtiva e Novas Relações Interfirmas na Cadeia Automobilística nos Anos 90", IN: Produto \& Produção. Vol 4. N. 3. Outubro. 2000.

PREVITALLI, F. S. As Relações de Subcontratação no Setor de Autopeças: um estudo de caso. Dissertação de mestrado. Campinas: IFCH/UNICAMP. 1996.

RAMALHO, J. R. "Precarização do Trabalho e Impasses da Organização Coletiva no Brasil”, IN: ANTUNES, R. (Org.). Neoliberalismo, Trabalho e Sindicatos: reestruturação produtiva no Brasil e na Inglaterra. São Paulo: Boitempo. 1998.

SEWELL, G. "The Discipline of Teams: the control of team-based industrial work through electronic and peer surveillance", IN: Administrative Science Quarterly, 43 (2), June. 1998.

TOMANEY, J. “A New paradigm of Work Organization and Technology?”, IN: AMIN, A (Org). Post-Frodism. Oxfrod: Blackwell. 1996 
*** As pesquisas são realizadas no âmbito dos Grupos de Pesquisa Trabalho, Educação e Sociedade, sob a coordenação da profa. Fabiane Santana Previtalli e História, Trabalho e Educação, sob a coordenação dos professores Carlos A. Lucena e Robson L. França. Nossos agradecimentos a todos os membros pesquisadores.

${ }^{i}$ Para maiores considerações sobre tipos de tecnologias, consultar Previtalli (2005 e 2006).

${ }^{i i}$ Inovações incrementais são aquelas que ocorrem sem resultado direto de uma pesquisa formal, mas através de pequenas mudanças no processo produtivo. Seus efeitos estão mais relacionados ao crescimento da produtividade. Consultar Previtalli (2005).

${ }^{\text {iii }}$ Segundo Balibar (1973), para que os meios de trabalho presentes no modo de produção sejam também indicadores de relações sociais, é importante que sua análise ultrapasse a mera mensuração de sua eficácia para o capital, medida apenas em termos de produtividade ou uma análise descritiva da tecnologia e seus elementos.

iv Assim, no Brasil, inserido de forma tardia e dependente no processo de expansão do capital e ocupando uma posição subordinada na divisão internacional do trabalho, a acumulação não foi assegurada por meio do chamado "compromisso fordista". Na verdade, grande parte da sustentação do taylorismo-fordismo e da acumulação capitalista da burguesia internacional se assentou na sub-remuneração e superexploração da sua força de trabalho. Ver Carvalho (1987); Humphrey (1993); Antunes (1998); Antunes (2000 a e b).

${ }^{v}$ Essas diferenças relacionam-se, entre outros elementos, à capacidade produtiva, à aquisição e adaptação do novo processo produtivo. Consultar Tavares (1982).

${ }^{\text {vi }}$ A última grande greve foi no inverno de 1937, quando os trabalhadores organizados no UAW forçaram a General Motors e outras grandes companhias a reconhecer o sindicato. Consultar Previtalli (2002).

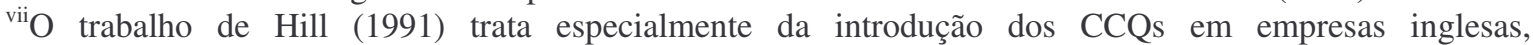
primeiramente como uma técnica isolada e posteriormente no bojo de um conjunto de mudanças mais sistêmicas, incluindo o TQM.

viii Entre os autores que apontam para a revitalização do trabalho, a requalificação e a tendência à redução da fragmentação do taylorismo-fordismo nas novas condições da produção estão Piores \& Sabel (1984), Kern \& Schummann (1992), Hoffman \& Kaplinsk (1988), Coriat (1988 e 1993), Womack et al (1990). 